\title{
Congenital Toxoplasmosis in Two Successive Sibs
}

\author{
APARECIDA G. P. GARCIA \\ From Instituto Fernandes Figueira, Rio de Janeiro, Brazil
}

Almost all cases of congenital toxoplasmosis result from acute infection of the pregnant mother, so that it seems extremely rare for a mother to give birth to more than one affected child (other than twins). We report here such a case.

\section{Methods}

Specimens were fixed in $10 \%$ formalin. Paraffin sections were stained with haematoxylin-eosin and by the Wright and Craighead method, as modified by Perrin, to demonstrate Toxoplasma gondii.

\section{Case Reports}

The mother was Portuguese, aged 31. She had had a stillborn child 9 years previously, and a healthy child 1 year previously. In the present pregnancy she had been admitted at the 5th month on account of a febrile illness, and investigation then had shown an abnormal oral glucose tolerance test. Blood Wassermann negative, group $\mathrm{A} R \mathrm{Rh}$ positive.

Case 1. Delivery (December 1962) was at the 7th month by caesarean section for fetal distress. At the time of the section an ovarian cyst was noted, and this was excised (see below).

The baby ( $2400 \mathrm{~g}$., $48 \mathrm{~cm}$.) was covered with meconium. The skin of the trunk showed many purpuric spots. The abdomen was enlarged, with marked hepatosplenomegaly. Respiratory distress was severe, death occurring at 24 hours. Baby's blood group, A $\mathrm{Rh}$ positive.

Necropsy. Lungs, voluminous, with few areas of aeration. Heart, enlarged, weighing $25 \mathrm{~g}$. (normal 18 g.); yellowish friable myocardium with scattered whitish areas. Liver, enlarged, weighing 235 g. (normal $105 \mathrm{~g}$.), dark yellow with smooth surface, abnormally firm consistency. Spleen, greatly enlarged, weight $52 \mathrm{~g}$. (normal $8 \mathrm{~g}$.), showing a uniform aspect on section. Brain, white-yellowish ulcerated areas, apparently calcified, and covered by slightly thickened leptomeninges, were present on the surface of the cerebrum. Sections showed similar lesions in the subcortical and periventricular zones, with slight dilatation of the lateral and third ventricles. There were no visible lesions in the cerebellum, medulla, pons, or spinal cord, or eyes.

Microscopical examination. Brain: sections from

Received June 4, 1968. cortex, ventricular walls, choroid plexuses, basal ganglia, and aqueduct of Sylvius were examined. The leptomeninges showed slight cellular infiltration, mainly perivascular (lymphocytes and histiocytes). In the cortex there were areas of necrosis, the destruction of nerve cells and glia being such as to leave mainly amorphous material mixed with calcium; at the periphery of these areas phagocytes with lipids and mononuclears were seen. Perivascular microglial nodules, formed by accumulation of cells with enlarged nucleus and scant, poorly delimited cytoplasm were found irregularly scattered through the nervous substance, mainly in the subcortical area. The ependyma had disappeared in many areas, and had been replaced by granulation tissue which projected into the ventricular cavity. The choroid plexus was oedematous, congested, and diffusely infiltrated by round cells. Numerous pseudocysts of toxoplasma were present. In the pons, medulla, and spinal cord there were numerous glial nodules without areas of necrosis, and pseudocysts were present. The cerebellum showed no lesions. Eyes: the choroid showed dilatation and congestion of vessels, with surrounding infiltration of round cells; the retina was oedematous, being extensively detached from the choroid. The optic nerve showed the same type of inflammatory exudate. No organisms were found. Lungs: showed resorption atelectasis, some hyaline material in the alveolar ducts, some alveolar haemorrhage, round cell infiltration surrounding vessels, and thickening of alveolar septa. Adrenals: in the internal cortical area and medulla there were foci of necrosis (Fig. 1) either nodular or as an enlarged band separating the cortex from medulla; in the periphery of the necrotic area there was some histiocytic infiltration. Away from these areas, were numerous pseudocysts. Heart: there was chronic diffuse cellular infiltration in the pericardium. The myocardium showed focal areas of cellular infiltration, with round cells and histiocytes; these were mainly localized in the interfibrillar septae. Fragmentation, hyalinization, and deposition of brown pigment were noted; many fibres were parasitized. In the endocardium and subendocardial zones histiocyte nodules were seen. Voluntary muscle: focal mononuclear perivascular infiltrations as well as pseudo-granulomatous lesions (histiocytes and epithelioid cells) were seen along with fibril destruction. The large number of parasitized fibres (Fig. 2), always without inflammatory reaction, was striking. Liver: the lobular structure was partially obscured by extensive erythropoiesis. The portal spaces were enlarged, with 


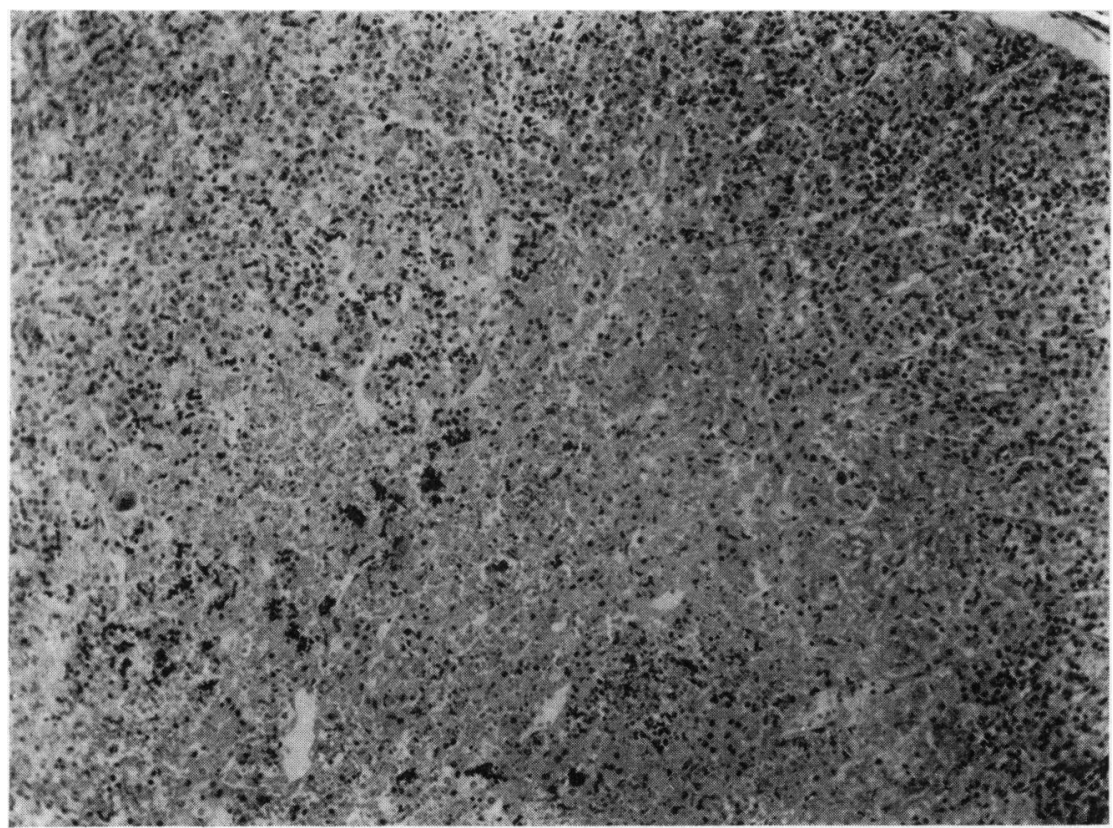

Fig. 1.-Case 1. Adrenal, internal cortical area, showing a nodular area of necrosis. (A pseudocyst, not discernible on reproduction, is also present. $)(H$. and $E . \times 73$.)

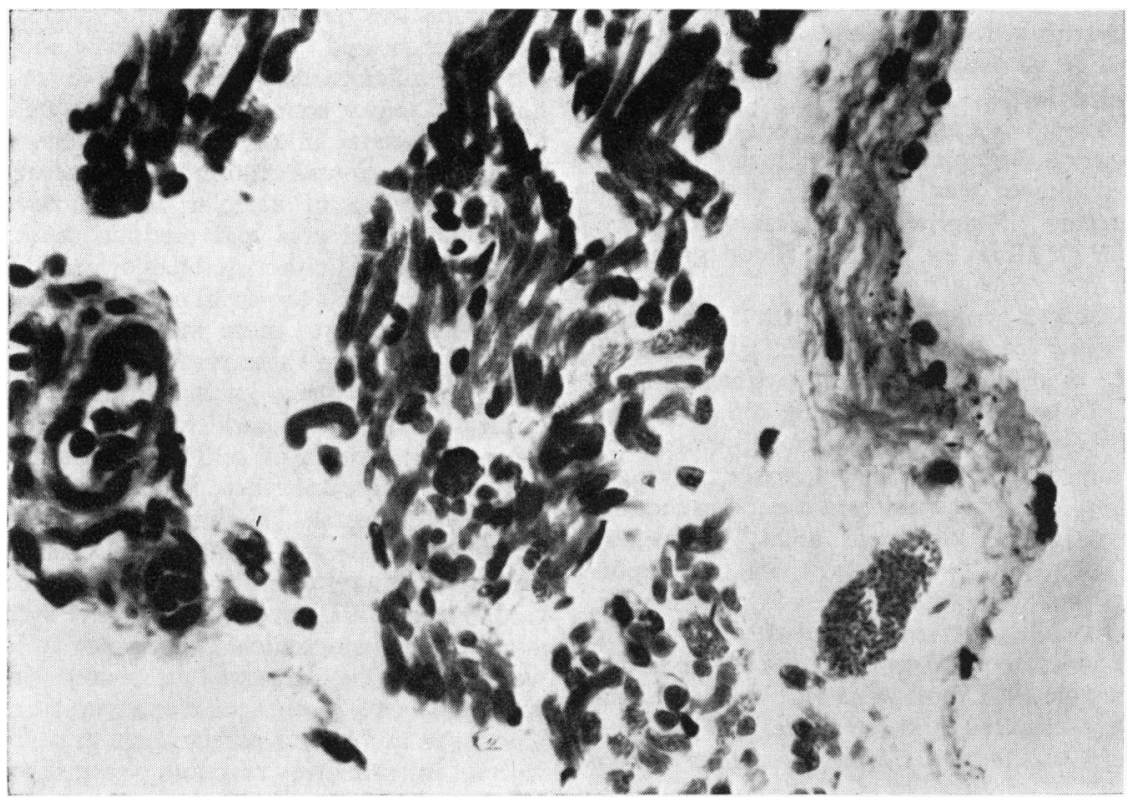

Fig. 2.-Case 1. Skeletal muscle, showing a parasitized fibre. (H. and E. $\times 320$. 


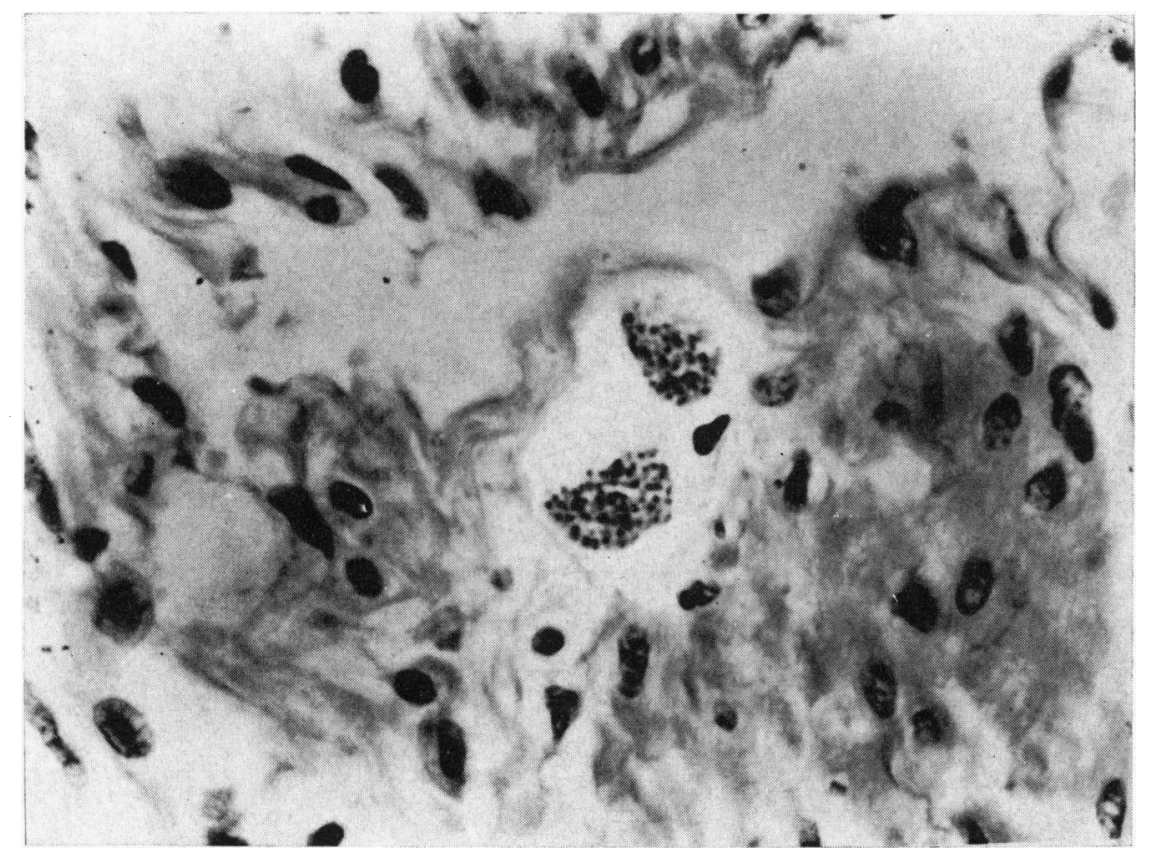

Fig. 3.-Case 1. Bladder muscle, showing two pseudocysts of Toxoplasma gondii. (H. and E. $\times 320$.)

peripheral bile-duct proliferation, and dense round cell infiltration (eosinophils and bile-macrophages). Marked bile stasis and focal cellular necrosis were seen in the parenchyma. No micro-organisms were seen. Spleen: uniform aspect was due to lack of lymphocytes. Kidneys: abundant interstitial mononuclear infiltration was present. Bladder: in all layers there were pseudogranulomatous lesions, some of which contained pseudocysts of toxoplasma (Fig. 3). Uterus: in the muscle there was perivascular cellular infiltration as well as granulomatous nodules, with a few cysts of toxoplasma. In the ovaries and tubes the only abnormality was a diffuse round cell infiltration.

Placenta: nodules formed by groups of villi connected by fibrinoid material with leucocytic infiltration were prominent. Toxoplasma were identified in the stroma of villi and in the endothelium of vessels (Fig. 4). The chorion was thickened, with vessels partially occluded by intimal proliferation. Histio-lymphocytic nodules around trophozoites of toxoplasma were conspicuous.

Umbilical cord: around the vein numerous pseudocysts were seen, as well as toxoplasma trophozoites (Fig. 5).

Maternal ovarian cyst: this was a lutein cyst; exhaustive search failed to show any toxoplasma.

In view of the toxoplasmosis revealed in this case, the mother was tested by intradermal toxoplasmin. Though three different types of toxoplasmin were tried, the test was consistently negative. (No other toxoplasma tests were available at that time.) She was given an 18-day course of pyrimethamine with sulphaphenazole.
Case 2. About 5 months after the delivery of Case 1, the mother became pregnant again, and this pregnancy ended in a spontaneous abortion at about 6 months in October 1963.

Necropsy. The fetus (female) weighed $450 \mathrm{~g}$. and measured $22 \mathrm{~cm}$. Maceration was advanced. The brain was grossly autolysed, and was covered with a golden-yellow grumous material There was some hepatosplenomegaly, but no other conclusions could be reached in view of the maceration.

Microscopical examination. The fetal organs being grossly autolysed, only the brain and adrenals yielded useful information. The adrenals showed numerous foci of necrosis and calcification in the cortex (Fig. 6); some pseudocysts, though modified by autolysis, were seen. In the brain there were numerous necrotic foci, mainly perivascular, and amorphous material staining positively for calcium, Kossa method. No toxoplasma were seen.

Placenta: the stroma of the villi was dense, and diffusely infiltrated by histiocytes, epithelioid cells, and small mononuclears, sometimes assuming a pseudogranulomatous aspect. Many villi showed degenerated epithelium, attached to other villi by fibrinoid material with leucocytic infiltration, and forming small nodules. Pseudocysts of toxoplasma were seen in the endothelium of vessels in stroma, and in the epithelium of villi. The chorion and amnion were thickened, with abundant cellular infiltration (histiocytes, lymphocytes, and macrophages), and trophozoites and pseudocysts of toxoplasma were again present (Fig. 7). It was noteworthy that only around the trophozoites was there any 


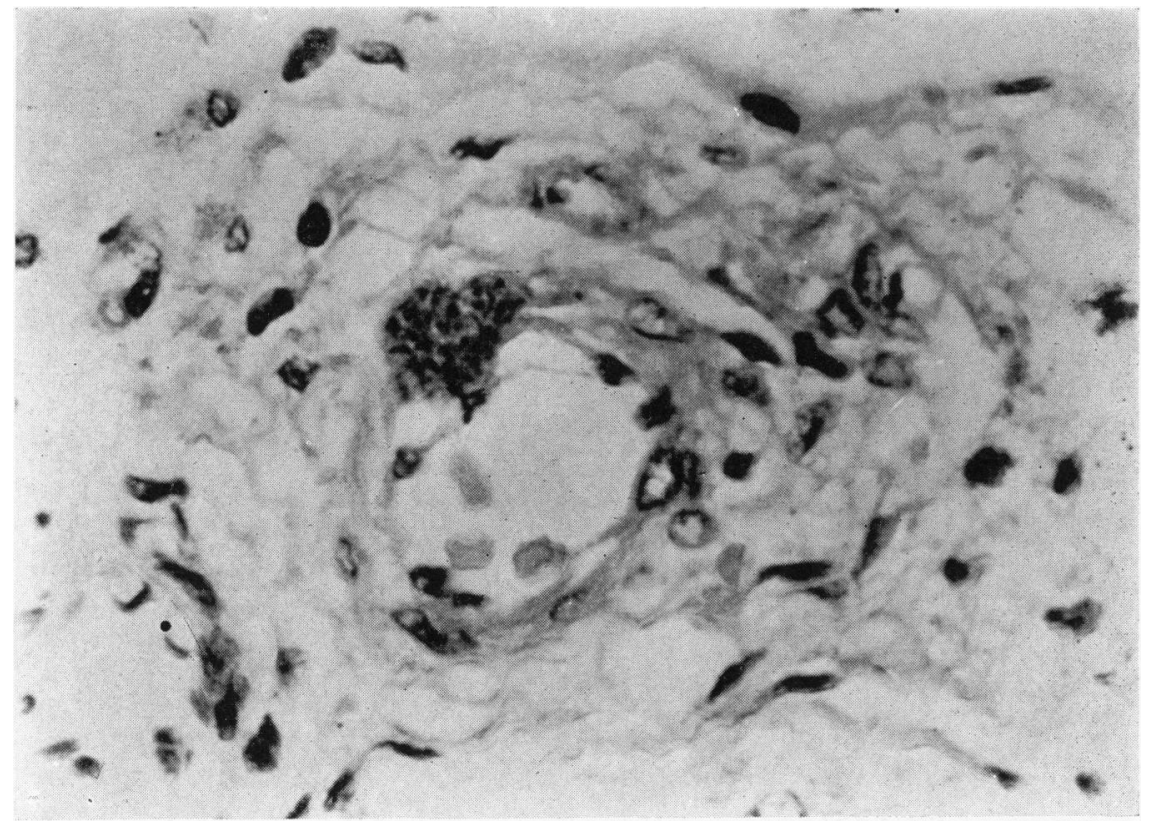

Fig. 4.-Case 1. A pseudocyst of toxoplasma in the endothelium of a vessel of a chorionic villus. (H. and E. $\times 320$.)

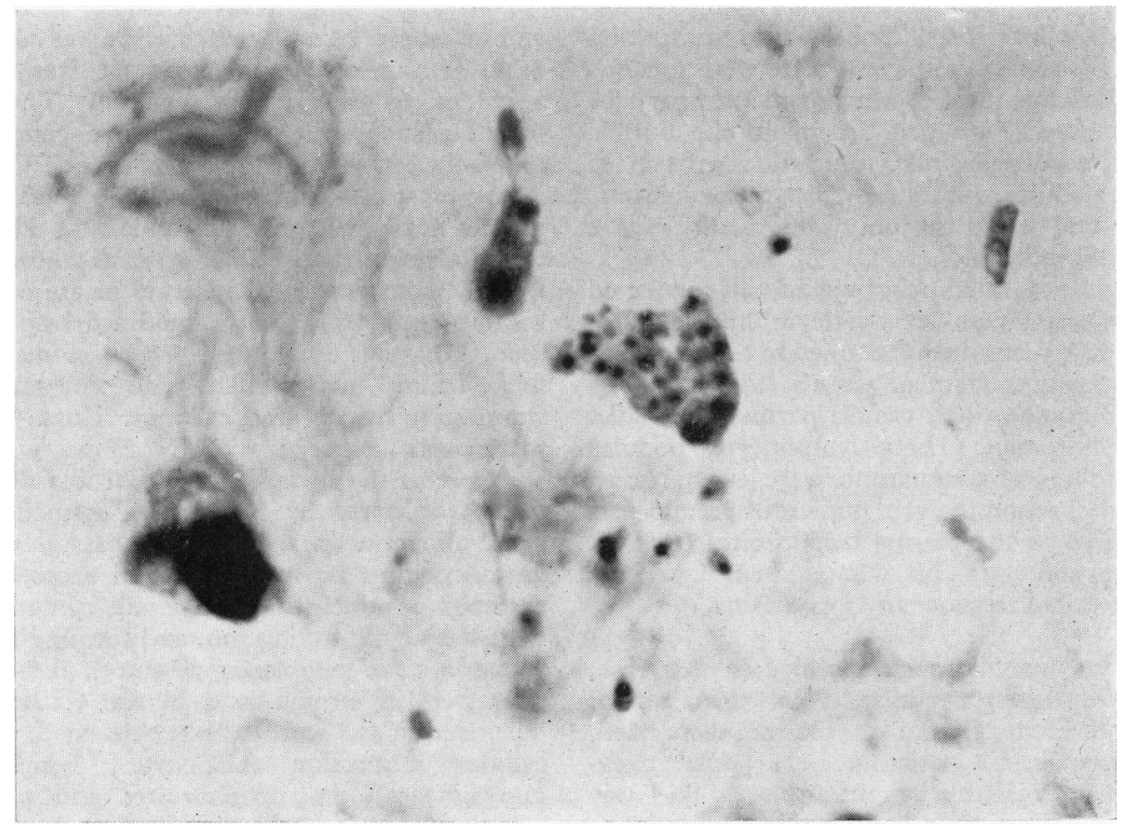

Fig. 5.-Case 1. Umbilical cord, showing trophozoites and a pseudocyst of toxoplasma. (H. and E. $\times$ 710.) 


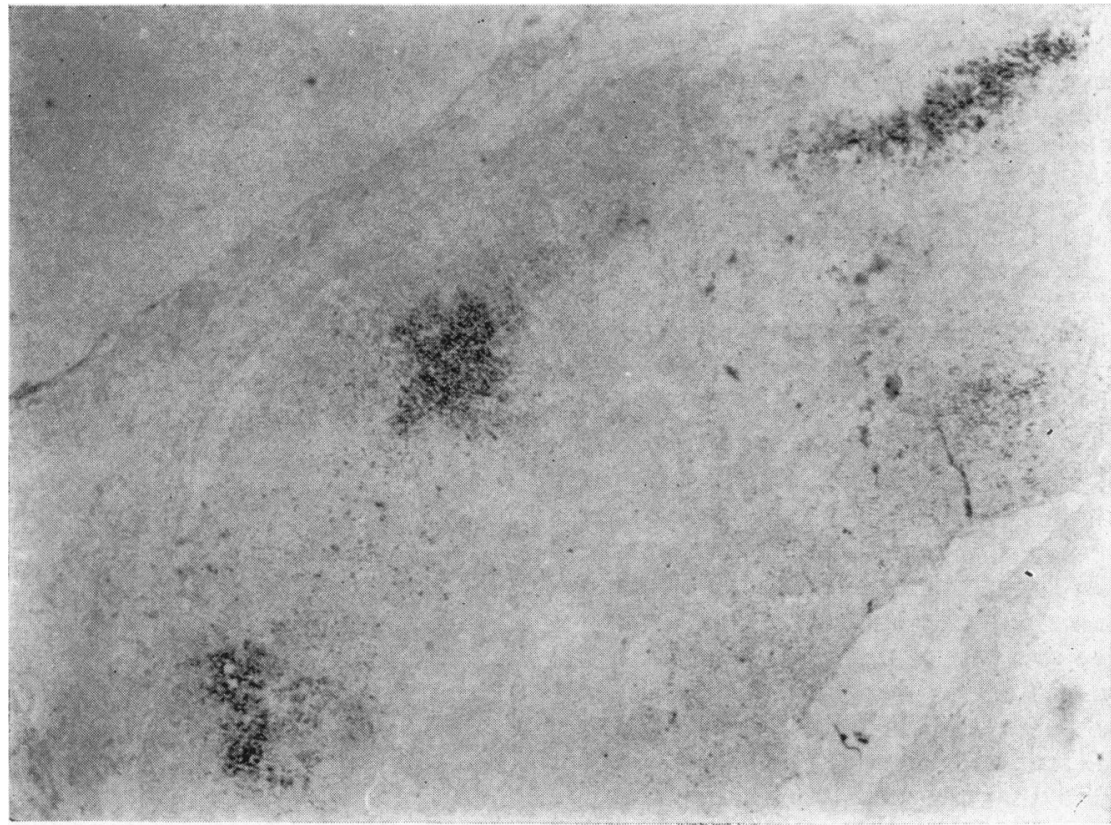

FIG. 6.-Case 2. Adrenal cortex, showing focal areas of calcification. (Kossa. $\times 26$.)

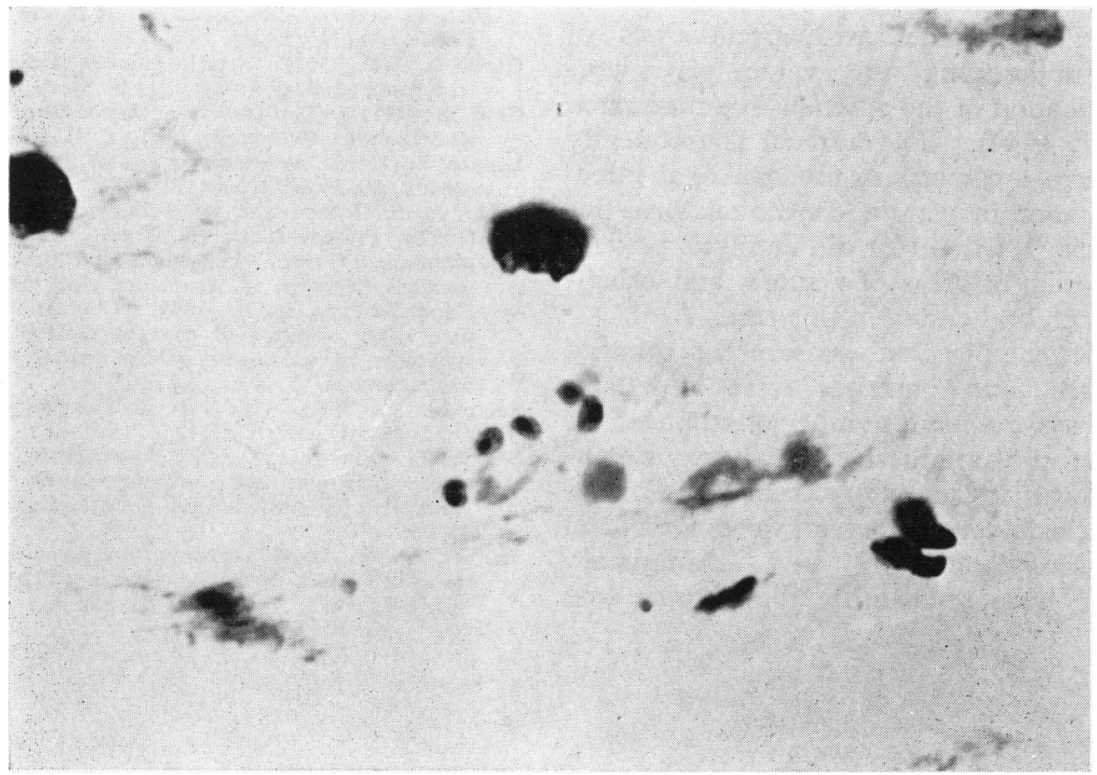

FIG. 7.-Case 2. Chorion, showing trophozoites of toxoplasma. (H. and E. $\times$ 710.) 
inflammatory reaction. In the decidua a few pseudocysts of toxoplasma were found. Umbilical cord: despite maceration, perivascular necrotic lesions, together with many trophozoites, could be identified.

The mother was re-examined in January 1965, 15 months after the delivery of Case 2, and serological toxoplasmosis tests were carried out (Dr. Nery Guimarães, Instituto Oswaldo Cruz). The Sabin-Feldman was positive 1/64. In August 1966 the test was positive $1 / 1024$.

There have been no further pregnancies.

\section{Discussion}

Though the toxoplasma was not isolated, macroscopical and microscopical lesions, and the widespread tissue infestation by the pseudocyst or trophozoite forms of toxoplasma, together with the maternal serology, provided acceptable evidence for toxoplasmosis affecting successive conceptuses.

The negative skin test of the mother, performed after delivery of Case 1, does not invalidate the diagnosis, for Sabin and Feldman (1949), Sabin et al. (1952), Beattie and Beverley (1960), and Gard (1951) all found that the toxoplasmin test might be negative in individuals with specific antibodies in serum. Furthermore, if the mother's acute infection occurred late in the first of the two pregnancies in this study (Case 1), testing in the puerperium might be too early to yield a positive result, since a positive skin reaction is known to appear late after infection (Ffrench, 1963).

In Case 2 it was possible, in spite of the maceration, to identify, in the adrenals, foci of necrosis and calcification, together with pseudocysts of toxoplasma, underlining the value of microscopical examination of the adrenals in a macerated fetus (Zuelzer, 1944). The adrenal is frequently the site of micro-organisms in prenatal fetal infections, for instance in certain congenital virus infections (Garcia, 1963). Nor did autolysis prevent the demonstration of areas of necrosis and calcification in the cerebral cortex in this case.

In both cases the placenta was severely damaged by the disease, and parasites were abundant. Conspicuous was the large number of trophozoites in the chorion and umbilical cord, always accompanied by focal inflammatory cells (histiocytes and mononuclears): pseudocysts were rarer and were not accompanied by any inflammatory reaction. We have found that the chorion and umbilical cord provide suitable material for inoculation studies, in the same way as amniotic fluid has been used (Schmidtke, 1957).

Evidence that more than one infant infected by toxoplasmosis may occasionally be born to a mother has been given by Langer (1963) and by Werner, Schmidtke, and Thomascheck (1963).

\section{Summary}

In a mother's two successive pregnancies, the products of conception, a liveborn premature infant and a 6-month abortion, infection with toxoplasma organisms was shown.

Where severe maceration of the fetus makes identification of toxoplasma organisms difficult, two tissues in particular should be examined histologically: (1) chorion of placenta and umbilical cord, where toxoplasma trophozoites and pseudocysts tend to be abundant; (2) fetal adrenals, where characteristic necrotic and calcified foci, as well as toxoplasma organisms, may persist.

We are grateful to Dr. Isnard Teixeira and Dr. Nery Guimarães for the laboratory tests made on the mother, to Miss Giselda Fonseca Lima for the bibliographical research, to Miss Maria Teresa Bartholomeu for the English translation, and to Mr. Mario Rocha for the photographs.

\section{REFERENCES}

Beattie, C. P., and Beverley, J. K. A. (1960). Discussion on toxoplasmosis. Proc. roy. Soc. Med., 53, 108, 111.

Ffrench, G. (1963). Toxoplasmosis, its nature and effects. Clin. Pediat. (Philad.), 2, 269.

Garcia, A. G. P. (1963). Fetal infection in chickenpox and alastrim, with histopathologic study of the placenta. Pediatrics, 32, 895 .

Gard, S. (1951). The laboratory diagnosis and epidemiology of toxoplasmosis. (Norwegian.) Nord. Med., 45, 352.

Langer, H. (1963). Repeated congenital infection with Toxoplasma gondii. Obstet and Gynec., 21, 318.

Sabin, A. B., Eichenwald, H., Feldman, H. A., and Jacobs, L. (1952). Present status of clinical manifestations of toxoplasmosis in man. Indications and provisions for routine serologic diagnosis. F. Amer. med. Ass., 150, 1063.

-, and Feldman, H. A. (1949). Chorioretinopathy associated with other evidence of cerebral damage in childhood. A syndrome of unknown etiology separable from congenital toxoplasmosis. F. Pediat., 35, 296.

Schmidtke, L. (1957). Nachweis von Toxoplasma in Fruchtwasser. Dtsch. med. Wschr., 82, 1342.

Werner, H., Schmidtke, L., and Thomascheck, G. (1963). Toxoplasma-Infektion und Schwangerschaft der histologische Nachweis des intrauterinen Infektionsweges. Klin. Wschr., 41, 96.

Zuelzer, W. W. (1944). Infantile toxoplasmosis with a report of three new cases, including two in which the patients were identical twins. Arch. Path., 38, 1. 